\title{
Human potential in the system of social and labor relations of the region in the context of the global digitalization of the economy (experience of sociological analysis)
}

\author{
Bashir Khubiev ${ }^{1}$, Zarema Atabieva $^{1}$, and Natalia Reshetnikova ${ }^{2,3 *}$ \\ ${ }^{1}$ H. M. Berbekov Kabardino-Balkar State University, 173, Chernushevskogo str., Nalchik, The \\ Kabardino-Balkarian Republic, 360004, Russia \\ ${ }^{2}$ Don State Technical University, 1, Gagarina, Rostov-on-Don, 344000, Russia \\ ${ }^{3}$ Rostov State University of Economics (RINH), 69, B. Sadovaya str., Rostov-on-Don, 344002, \\ Russia
}

\begin{abstract}
The article summarizes the findings of a sociological study on the labour relations problems in a particular region of the North Caucasian Federal District. The integration processes of various scientific directions that study labour and employment relations, contradictory trends in approaches to the analysis of labour activity, satisfaction and labour productivity are revealed. The article analyzes the respondents' opinion about the employment activity of the labour subject, his labour behaviour, base economic indicators and intellectual resources of the regional society. The authors note the dependence and interdependence of the Russian economy crisis and labour relations, especially the content of labour and its cost. For a total, these factors balance the income level of the working population, and the break-in economic ties between the regions have created noticeable disparities in the key indicators of employment and living standards. The authors give a special place to the characteristics of the carrier of labour relations, the level of activity, the main channels for the use of personal qualities and intellectual abilities. The concentrated expression of these categories of qualities, to which attention is drawn in the article, is the individualization of work activity and the simultaneous ability to work in a team. It is noted that both the creative qualities of the employee and the ability to realize talent in the workplace are manifested in these categories. In the modern world, social philosophy, sociology and other areas of human knowledge are in constant search of a balance between attractive prospects for transforming social reality under the influence of technology and the risks of manipulating human consciousness and his behaviour in a society of mass communications and big data.
\end{abstract}

\footnotetext{
*Corresponding author: nata.dstu@yandex.ru
} 


\section{Introduction}

Global digitalization of the economy, on the one hand, is the basis for the innovative development of modern economic systems.

At the same time, it creates new threats and risks for global and national security.

The article describes the branches of production where the participants of the sociological survey are involved and the degree of manifestation of their professional and personal qualities.

The respondents received conflicting judgments about the possibilities to realize their labour talent and competencies. About half of the respondents confirm this possibility, and one third does not consider it possible, and the reason for this is the lack of proper motivation. This segment of employment relations is correlated with the estimated parameters of the formal and informal economy. The authors give attention to the characteristic of the social and environmental involvement of the labour subject in employment relations. This aspect is based on the respondents' opinion about their talent in the workplace. The degree of satisfaction with work and work results in the form of wages, from the point of view of the respondents, is in direct proportion to the motivation of work.

\section{Materials and methods}

Labour and employment relations in society have always attracted the attention of representatives of various branches of science.

This article is based on the materials of a large-scale sociological study conducted in 2019, on the topic of Labor and economic life in the republics of the North Caucasian Federal District of the Russian Federation. The study was carried out with the financial support of the Russian Foundation of Basic Research within the framework of the research project Labor and Economic Activity in the Russian Federation in the Conditions of Crisis. The aim of the study is to create a matrix of public opinion and the direction of the mass consciousness, allowing for an examination of the understanding and the real state of the internal connection between work and welfare. This segment was the pivotal line for the disclosure to find the key elements of social and labour relations in the regional society. The task is solved based on the materials of the Kabardino-Balkarian Republic regarding data on other republics of the North Caucasian Federal District when the need arises to support the hypothesis or concept put forward.

It should be noted that the problem of social and labour relations is becoming one of the discursive in modern economic and sociological literature.

A review of the literature on the selected topic has shown that the role and significance human potential in the system of social and labor relations of the region are discussed in many papers of such scholars as Chechenov et al. [1], Kumykov et al. [2], Volkov et al. [3], Lokova et al. [4], Reshetnikova et al. (2021) [5], Reshetnikova et al. (2019) [6], Reshetnikova and Magomedov [7].

The interest in the sociology of employment, the problems of sociological and sociophilosophical understanding of labour processes and relations are being actualized, the theoretical and methodological base of the sociology of labour is expanding.

In the scientific discourse, the concepts of «work», «working life», «work activity» does not fit into the framework of any of the existing scientific disciplines.

To study human labour activity, issues of ensuring its efficiency, safety, comfort, attempts are being made to integrate such scientific areas as economics, sociology, economic sociology, sociology of labour, ergonomics (the science of labour, which studies the labour activity of a person). The desire for interdisciplinarity is especially demonstrated by economic sociology and the sociology of labour, although in fact, both branches develop 
on their own. In this case, the object of study is the role of the subject in the socioeconomic space, his labour activity, the form of economic behaviour, as well as socioeconomic inequality, the socio-cultural context of economic activity, etc. Ye. G. Zhulina rightly emphasizes that along with the relative resistance to the impact of the global crisis, the situation in Russia is characterized by «an exacerbation of contradictions in the system of social and labour relations, caused primarily by the conflicting interests of their subjects, which entailed ... an exacerbation of social tension, and as a result - demotivation of workers to work» [8]. By the contradictory interests of the author, presumably, he means social stratification in society to a critical level, the level of wages and unemployment. These aspects are considered in the article from the point of view of the opinions of specialists from the leading sectors of the economy and social sphere of the region.

The problems of labour relations and economic life in the republics of the North Caucasus are being actively studied by specialists in different directions, various social and economic indicators are analyzed, strategies are being developed to overcome the accumulated problems.

The systemic nature of the Economic crisis and the importance of taking into consideration all key factors in solving the problems facing the regions are especially emphasized [9]. The method of statistical analysis investigates the tension in the labour market [10], the socio-economic aspects of the formation of the labour market, the dynamics of economic and demographic indicators [11]. There are works where a strategy is being developed to overcome the chronic reproduction of the economic backwardness of concrete regions. In particular, Kh.V. Dzutsev [12], Yu.N. Sagidov [13] conclude that it is necessary to pay special attention to the problems of improving social relations, which determine the mood of society for development to the same extent as stimulating economic processes. The problem with most studies of the economic life of the North Caucasian region is that specialists start from statistical, economic and demographic indicators without taking into account values, behaviour trajectories and opinions of the population itself, without relying on real pressing problems of citizens, fears and expectations. This work is to some extent fill this gap.

The objects of analysis of the presented article are the key indicators of the function of labour, labour results, the level of labour activity and labour behaviour, characteristics of the labour subject: social, professional, educational, age.

The labour relations system is investigated in almost all major industries: industrial, agro-industrial, digital technologies, science, education, government apparatus, law enforcement agencies, business, healthcare, services, management.

\section{Results}

The situation in the sphere of social and labour relations is aggravated by the fact that the Russian economy is going through a protracted crisis, and it is increasing its lag behind economically developed countries.

The socio-economic reforms of the past thirty years have significantly affected the range of labour problems and the perception of their relevance by workers and employers. Over the past years, the usual system of social stratification collapsed, which affected the content of labour and wages. Labour is not only a means of self-realization as a means of survival.

These general trends are manifested in different ways in different regions of Russia.

A group of scientists from the Center for Sociological Research KBSC RAS, identifying the most pressing problem among the population of the KBR, $64 \%$ of experts indicated a low level of income [14]. The lack of interregional economic ties has led to a significant disparity in principal economic indicators. Sufficiently rich regions coexist with poor ones, 
including the republics of the North Caucasus. The regional material and intellectual resources should have formed a solid basis for progressive growth, to achieve positive indicators of the standard of living and the quality of life. However, the reality suggests otherwise. The absence of a state strategy for ensuring the synchronization of development of Russian regions does not allow to fully use of the existing potential. As a result, the national republics of the North Caucasian Federal District were included in the number of eight constituent entities of the Russian Federation, in which workers with wages below the minimum wage prevail [15]. The Federal District, like no other region of Russia, needs to improve the economic indicators of labour and labour relations. Horizontal and hierarchical indicators of these relations are revealed in the article by methods of diagnosing public opinion about the relationship between labour and social well-being.

Each labour, even the simplest one, is complex, just as each of the potential carriers of labour is complex, be it an employee or an individual. In the process of labour, contacts of people occur, either belonging to the same profession or representing different types of labour and profession.

It is known that in the sociology of labour, along with the existing forms of labour and their dynamics, relations inherent in labour as a special social system are also studied. A special place in this system is occupied by the relations that develop between the subjects of labour, regardless of the performed labour powers, and which are realized, inter alia, in the process of interaction and direct communication. Each employee is able, through communicative actions, to influence others, induce action and persuade them to behave desirably, to make a choice of behaviour voluntarily. "When people independently acknowledge the correctness of the decisions that are to be implemented, it means that they have been influenced», writes the American scientist I.K. Adizes [16]. These words emphasize the role of interaction and cooperation in the work process. As a result, a special working environment is created - a microclimate where collectivism is characteristic and where there is a constantly repeated interaction of working people with each other. In this process, not only personal needs for work and its results in material terms are realized. A special place is occupied by the realization of personal needs in establishing contacts or even friendly relations with other employees. To the question «Does your job allow you to establish friendly contacts with other people?» $88 \%$ of the respondents answered unequivocally positively. After all, one of the most important functions of labour as such is the formation of the individual as a social being, in the words of a classic, society «is nothing more than the education of a person by human labour».

From the main prerequisite for life and a source of livelihood, work turns into the general way of self-expression of a person as an internal need becomes a significant factor in friendly (along with production) contacts.

For the realization of the personal qualities of an employee in the labour process, not only the presence of individual competencies but also the quality of the collectivity of the individual is of particular importance. These qualities and production behaviour of an employee in the sociology of labour are determined by his place in the organizational system, as well as the level of development of personal qualities [17]. Studying the designated aspects of labour relations, the authors analyze the social creativity and social activity of the labour part of the regional society in the context and through the prism of the trajectory of the everyday work of people, their opinions and views on the role of labour and value judgments about really existing labour relations, really pressing problems of the working person.

In this vein, it was important, first of all, to study the content of labour, the socioenvironmental characteristics of personal involvement in labour relations, which accompany the manifestation of professional talent, or, on the contrary, hinder it. 
Almost half of those employed (44\%) believe that they have the opportunity to show their talent in the workplace. At the same time, $30 \%$ of them deny the possibility of fully realizing their talent, since labour talent is the highest level of self-realization, which is often not possible to reach due to lack of proper motivation. At the same time, the level of labour activity was also assessed; to what extent it (activity) uses intellectual capabilities. In total, $76 \%$ of the respondents believe that labour activity and intellectual capabilities unconditionally coincide (42\%), and $34 \%$ of the respondents do not fully use their intellectual abilities in work. Negatively assessing the relationship between the type of work and personal intelligence, a group of respondents $(8 \%)$ agree that «limited powers and the burden of responsibility» do not leave room for the demonstration of intelligence and talent.

The object of study was also social and labour relations as forms of interaction between subjects within the framework of the division of labour.

In the structure of the regional economy, as is known, the informal and public sectors are represented. The study carried out a comparative analysis and estimated parameters of the formal and informal economy through the positions of the respondents. The data show approximate equality of the positions of those who prefer this or that sector of the economy: $32 \%$ of the respondents give preference to the informal economy, $42 \%$ - to the public sector. Both have positive and negative judgments. In particular, it is noted that the informal economy provides freedom both economic and political and in the public sector, a person feels stability and some confidence in the future. In both cases, wages are an incentive for choosing a career path.

The attitude to work, both creative and non-creative, is objectively motivated by material reward or profit.

Remuneration for workers in various spheres and systems - state or non-state - has always been considered as an incentive for choosing a type of professional activity and personal career goals. The choice of a variant of his behaviour by a person depends, according to experts, mainly on what is the driving motivational force for him in the labour process. If we proceed from the basic constant of the concept of «motivation-motive», then from the set of its components, as a rule, an internal state, called a need, is singled out. Behaviour is stimulated by the need that dominates at the moment. The need for material incentives, expressed in decent wages, accompanies a person throughout the entire labour process. Even in the presence of all positive indicators of personal qualities (the need for work, enterprise, professional knowledge, skills and abilities, creativity, etc.), the results of labour will be ineffective if the employee is dissatisfied with the wages. Studying the level of remuneration for work and the degree of satisfaction, it was found that half of the respondents $(50 \%)$ are quite satisfied with their wages. But attention is also drawn to the fact that there are quite a few of those who are not satisfied with it - almost every third $(32.0 \%)$. Many of those who are satisfied with the wages emphasize the idea that the motives that cause labour activity are set by the entire previous course of professional and personal development - the desire to achieve a high level of professionalism. «If you are a professional», some respondents note, «then your services will be in demand and, therefore, will be paid accordingly».

As one of the key questions to identify the conjugation of individual human efforts to achieve material well-being and the state of the regional economy, we posed the question «Does work give you a sense of stability to maintain family income?»

The respondents' answers, again, contain diametrically opposite assessments of the existing reality. For example, $46 \%$ of the respondents assess their work as fully providing a sense of stability to support the family budget. "The family income is stable», they say. The feeling of stability still prevails, although there is no confidence in the future. Too many unpredictables in life. "Approximately the same number - 44\% - consider it to be 
satisfying, but not fully. «There is nothing more precious than a sense of the real state of stability of the family, moral and material. Unfortunately, not all families covered by these valuable qualities»».

In the conditions of a post-industrial economy, the essence and content of the concept of production are rapidly changing.

The integration of methods of economic sociology and sociology of labour significantly expands the discourse in the production of high technology products. Experts believe that high-tech production is a motivational factor in encouraging an employee to engage in active labour behaviour. Due to the development of economic sociology methods and sociology of labour, the discourse in the sphere of production is expanding significantly. The production of intangible goods is increasingly being used, the media industry is especially noticeable, which has developed on an industrial scale. In total, these innovations in the field of production have given rise to a tendency to call modern society informational. The study found that high technologies are widely used in manufacturing enterprises, in the spheres of management, medicine, education, and the banking system. Many types of work are accompanied by digital technologies, which, according to the respondents, have a great future, as a special direction the digital economy stands out, also defining it as a promising direction in economic development. This prospect is supported by the fact that in the regional society, as shown by the survey results, the proportion of those employed in intellectual work amounted to $66 \%$, and those employed in enterprises with modern digital technologies make up $40 \%$. In the republics of the North Caucasian Federal District, according to our data, the proportion of such enterprises varies from $9 \%$ to $38.8 \%$ [15].

These data indicate that in modern society, knowledge is applicable in all areas of work.

Science is in demand not only among the bearers of the scientific profession but also among those who, through the acquired profession, embody it into practice every day, serving to improve both knowledge and work skills.

\section{Discussion}

In modern society, a new type of employed person is being reproduced, which successfully represents the «knowledge economy» in various spheres of work.

Among the variety of types of work in the age of information technology, creative types of work are becoming dominant. Labour makes increased demands on the mental creative activity of the employee. This is the reality of labour relations today. "The Russians are interested in the development of human capital, in competition and equality of opportunities, writes Yu.G. Volkov. In other words, they want to live in a society where everyone can show their talent» [18]. Relying on his creative abilities and the existing system of knowledge, a person of labour in any area of production objectively strives to master the market for high technology products. The acquired knowledge at the initial stage of entry into labour relations is changing rapidly towards an increase in the intellectual segment of labour. The study revealed that in the opinion of $58 \%$ of the respondents, work allows them to expand their knowledge, that the work process affects the acquisition of previously unknown knowledge about the subject of work. Here is one very rational point of view that fully characterizes the innovative type of economic behaviour and creative work. «Any kind of work requires a creative approach. In the field of mental labour, there is no knowledge given once and for all, it requires constant improvement, an innovative approach to methods and labour techniques, then the work will bring more benefits to both sides of the participants in the labour process»».

An important component of the problem of labour relations, and of the economic life of society as a whole, is labour resources and their segment - the quality of the labour force. 
There is no need to prove the importance of labour resources as an economic category and an integral part of human capital. The quality of the labour force is also an indicator of the level of qualifications and the most significant factor in meeting the needs of high technology production. The state of the labour potential of society, its educational and creative levels, professionalism and entrepreneurial activity - these are the components that provide a long-term impact on the productivity and quality of labour, the economic life of society as a whole. In addition, the formation of a stable workforce is impossible without the availability of workers who can constantly improve their knowledge, retrain if production requires it. In such a situation, employers focused on democratic principles of labour organization strive to provide jobs following the training profile, but taking into account the ability of workers to learn quickly, and maybe retrain, in the process of work. To maintain the competitiveness of its products in the context of an innovative type of transformation of production technology, the employer strives to increase the intellectual level of the employee and the share of his creative functions for the operational use of the constantly updated knowledge system. It is clear that for this the employer must have an appropriate source of replenishment of the labour force. One of such sources of employees' prompt response to changes in technologies following the labour market requirements is the retraining of their employees, without replacing the existing staff with new employees. The study examined the situation at enterprises and organizations of the republic on the observance of such an approach to workers. The survey data indicate the active use of the practice of retraining or advanced training of workers, and the share of those who answered positively on this issue is $58 \%$. The following assessment of the situation deserves attention: "Professional retraining... is the norm in our team. At the same time, those who fail to meet the requirements for the quality of labour are replaced by others" [15]. It should be borne in mind that intellectual work, as a rule, is individual, and, of course, it is not necessary to count on the mass manifestation of the talent and creativity of people. And the need for a creative form of labour is constantly in dynamics, outstripping the growth of creative thinking, capable of innovative labour methods. Therefore, along with measures to retrain or improve workers qualifications, employers are looking for creative, creativeminded workers.

The Kabardino-Balkarian Republic has always been one of the regions with a high level of education. According to data for 2007, almost a quarter of citizens have a higher education or an academic degree [19].

University education is viewed by the population as a condition for increasing social status and positions. Most universities are focused on innovative practice, especially in digital technologies and management in various sectors of the economy and social sphere. We can confidently say that the education system in the region is capable of training labour personnel for modern high-tech and science-intensive industries act as an agent of innovative technologies, new professional and life practices.

\section{Conclusions}

The conducted research is identifying the quality of labour resources in the KabardinoBalkarian Republic shows the paramount importance of those accents that the education system sets.

Perhaps the decisive role belongs to a graduated system that takes the most talented young people to the point where they can work in science and generate new ideas. $60 \%$ of the respondents gave a positive answer to the question about the readiness of citizens of the $\mathrm{KBR}$ to the requirements of employers to have the ability to learn quickly. These data indicate the high potential of the region's labour resources and their readiness to participate in social and labour relations within the framework of the division of labour. 
With a solid labour potential, the regions of the North Caucasus experience an acute shortage of jobs.

Unemployment has become a destabilizing factor in economic life. In the KabardinoBalkarian Republic, in particular, the traditionally high labour surplus is due to insufficient development of economic potential and an acute shortage of its own investment resources for updating and modernizing fixed assets and creating new jobs [20]. Given this circumstance, the authors in the course of a mass survey were faced with the task of studying the opinion of the respondents about the unemployment rate. With knowledge of the objective state of the situation, the respondents assess unemployment in the republic as critical (24\%), the unemployment rate is high at $56 \%, 12 \%$ of the respondents bring it to the same level as in the country as a whole. In the republics of the North Caucasian Federal District, the results of a similar survey generally fit, if we sum up the indicators of the "critical" and "high" levels - from $30 \%$ to $40 \%$. The exception was the Republic of Ingushetia, where $54 \%$ of respondents consider unemployment to be at a critical level, and the Chechen Republic, where this figure is only $6 \%$ [15].

It should be noted that the availability of a job does not guarantee stable employment.

In the event of a decline in production and the need to bring the situation to an optimal state, a reduction in the number of employees will inevitably follow. This segment of the labour market, as the survey shows, turned out to be the most painful, $82 \%$ of the respondents note a high degree of risk of losing their job, it is far from easy to keep a job in the conditions of the economic crisis and labour surplus. This circumstance multiplies the philosophical essence of the fairness of the positions of the respondents: only human labour, the use of their knowledge, creative abilities and professional skills can ensure a stable standard of living and socio-economic development of society. Unfortunately, the Kabardino-Balkarian Republic, which has a huge potential of labour resources, among which, as noted, the representatives of intellectual labour predominate, was unable to use the available labour resources. As a result, it is among the outsider republics in terms of the main indicators of the level and quality of life of the population.

In conclusion, we also note the representation in the structure of production of the potential of the knowledge economy and information technology.

The data indicate the limitations in the regional economy of workers in informatization and the economy of knowledge. From this, it can be concluded that there is a weak presence in the regional economy of the unity of knowledge, technology and scienceintensive technology as a system. The respondents point to the absence of a scientific organization of labour at many enterprises of the republic, the network format "science education and business" is weak, as a result - the production of high technology products is limited. These aspects, of course, require in-depth study in the future, especially in the context of the impact of the knowledge economy on the employment rate.

\section{References}

1. A. M. Chechenov, et al., Digital Future Economic Growth, Social Adaptation, and Technological Perspectives, 111, 59-69, (2020), DOI: doi.org/10.1007/978-3-03039797-5_7

2. A. M. Kumykov, et al., Espacios, 38, 28 (2017)

3. Y. G. Volkov, et al., International Journal of Environmental and Science Education, 11, 9586-9597 (2016)

4. M. Y. Lokova, et al., Lecture Notes in Networks and Systems, 57, 176-182 (2019), DOI: doi.org/10.1007/978-3-030-00102-5_18 
5. N. Reshetnikova, et al., IOP Conf. Ser.: Earth Environ., 666, (2021), DOI: doi.org/10.1088/1755-1315/666/6/062139

6. N. Reshetnikova., et al., Lecture Notes in Networks and Systems, 57, 294-308 (2019), DOI: doi.org/10.1007/978-3-030-00102-5_31

7. N. N. Reshetnikova, \& M. G. Magomedov, Smart Innovation, Systems and Technologies, 138, 399-408 (2020), DOI: doi.org/10.1007/978-3-030-15577-3_39

8. E. G. Zhulina, Extended Abstract of Candidate (Econ.), PhD Thesis, 46, (2011)

9. M. A. Bagomedov, Regional Problems of Transforming the Economy, 11, 91-99 (2017)

10. R. Kh. Il'yasov, Kh. M. Yusupova, Competitiveness in the Global World: Economics, Science, Technology, 11, 174-178 (2017)

11. Sh. M. Gimbatov, Regional Problems of Transforming the Economy, 8, 48-54 (2017)

12. H. V. Dzutsev, 211 (ROSSPEN, Moscow, 2012)

13. Yu. N. Sagidov, Regional Problems of Transforming the Economy, 10, 23-37 (2017)

14. A. V. Kushkhabiev, et al., Nalchik, 66 (2019)

15. Z. A. Atabieva, et al., Dzutsev, 237 (ISPR RSA, Moscow, 2019)

16. I. K. Adizes, M., 285 (2015)

17. K. V. Vodenko, et al., M., 64 (2018)

18. Yu. G. Volkov, M., 101 (2017)

19. I. Sh. Dzahmisheva, Z. R. Afaunova, Nalchik, 85 (2007)

20. L. T. Eleev, Nalchik, 115 (2007) 